\title{
Effects of ball kicking dual task training on gait performance and balance in individuals with chronic hemiparetic stroke
}

\author{
Minseong Kim, Jaehun Shim, Kyunghoon Yu, Jiwon Kim \\ Department of Physical Therapy, The Graduate School of Baekseok University, Seoul, Republic of Korea
}

Objective: The purpose of this study was to compare the effect of ball kicking dual task gait training with the addition of a cognitive task with general treadmill gait training (TGT) on gait speed, gait endurance, functional gait, balance and balance confidence in patients with chronic hemiparetic stroke.

Design: Randomized controlled trial.

Methods: Fourteen stroke patients who volunteered to participate in this study were randomly divided into two groups with seven patients in each group: ball kicking dual task training (DTT) group and TGT group. The DTT group received ball kicking DTT with cognitive tasks consisted of three stages and the TGT group received TGT using normal walking speed, respectively, for 30 minutes per day 3 days per week for 4 weeks. Outcome assessments were made with the 10-meter walking test (10MWT), 6-minute walking test (6MWT), functional gait assessment (FGA), Berg balance scale (BBS), timed up and go test (TUG), and the activities-specific balance confidence (ABC) scale.

Results: The DTT group showed more significant improvement in the 10MWT, 6MWT, FGA, BBS, TUG, and ABC than the TGT group $(p<0.05)$. In addition, within groups comparison showed significant improvement in all variables $(p<0.05)$.

Conclusions: The findings suggest that both ball kicking dual task gait training and TGT improve gait performance and balance in patients with chronic hemiparetic stroke. However, ball kicking dual task gait training results showed more favorable outcomes than TGT for chronic hemiparetic stoke patients.

Key Words: Balance, Dual task performance, Gait, Stroke

\section{Introduction}

One of the physical effects of stroke patients is impaired balance, leading to the experience of 5 falls within on year after the first stroke event, which may cause secondary damage such as hip fractures [1]. In general, walking is considered as a dual task performance, such as talking while walking, and transferring of objects [2], and since the elderly and stroke patient population have balance impairments, they may have difficulty carrying out dual-tasks, and may experience falls, and may experience falls [3]. In particular, due to a decrease in dynamic balance, persons with stroke exhibit an inefficient walking pattern [4]. A person with stroke may present with gait characteristics such as asymmetrical posture creates an unequal single limb support phase, which will increase the energy consumption and will create a risk of falling $[5,6]$.

In addition, persons with stroke show a significant decline in gait velocity [7], the normal walking speed is from 20 to 70 for about $1.3 \mathrm{~m} / \mathrm{s}$ (male, $1.33 \mathrm{~m} / \mathrm{s}$; female $1.27 \mathrm{~m} / \mathrm{s}$ ), the average gait speed for persons with stroke is $0.23-0.73 \mathrm{~m} / \mathrm{s}$ [8]. Because persons with stroke experience difficulty performing their individual roles within the community [9], most persons with stroke consider that the recovery of their

Received: 31 October, 2016 Revised: 27 November, 2016 Accepted: 7 December, 2016

Corresponding author: Minseong Kim

Department of Physical Therapy, The Graduate School of Baekseok University, 69 Bangbae-ro, Seocho-gu, Seoul 06695, Republic of Korea Tel: 82-2-961-4700 Fax: 82-2-961-4701 E-mail: intothept@hanmail.net

(c) This is an Open-Access article distributed under the terms of the Creative Commons Attribution Non-Commercial License (http://creativecommons.org/licens es/by-nc/4.0) which permits unrestricted non-commercial use, distribution, and reproduction in any medium, provided the original work is properly cited.

Copyright $@ 2016$ Korean Academy of Physical Therapy Rehabilitation Science 
gait is the rehabilitation goal $[2,5,10]$.

There are several studies conducted on investigating the recovery of gait abilities, one of them being focused on the performance of dual-task training to improve gait and balance $[2,3,9]$. Dual-task training is comprised of the performance of one basic task with the addition of one or another task simultaneously [11]. Current studies with stroke patients have shown improvements in gait velocity, stride length, cadence and other spatio-temporal parameters [12]. A study by Cho et al. [7] has reported that body weight-supported treadmill training with ball kicking improved the lower extremity strength of the affected side as well as gait velocity and balance abilities in persons with stroke. Although dual-task training is mainly focused on motor tasks, recent studies are showing that exercise training combined with cognitive tasks has a positive effect on gait performance and balance abilities $[2,4,13]$.

Performing a dual-task involves the interference between the primary and secondary task, which shows a cognitive-motor interference effect, which implies that there is an interference when performing both the motor task and cognitive task simultaneously [13]. In particular, performing a cognitive task while walking has an effect on gait parameters, such as reduced gait velocity and increased doublelimb support time [2,14], which also has an effect on an individual's ability to go out into the community and cross the cross-walk there is a time restraint. Therefore, enhanced gait and balance abilities developed through performing dual tasks may assist a more stable and safe return to the community [9]. Study results showing positive effects of cognitive-interference training on gait performance and the ability to perform the activities of daily living in patients with neurological deficits exhibit the need for dual-task training $[4,15]$. In addition, since the ability to perform daily life activities is dependent upon balance abilities and risk of falls, there is a need for improvement of balance through a combined exercise program with cognitive training tasks [16].

If automatic movement arises through repetitive gait training, the effectiveness of cognitive interference training, dual-task performance focused on task-oriented gait training may improve gait speed and coordination $[17,18]$. In addition, other studies have reported the improvement of gait and balance through training with use of a ball or rings, or obstacle courses or the performance of dual-task training with virtual reality have reported improved balance and gait in persons affected by stroke $[9,11,12,15,16]$. Wulf et al. [19] reported that training with use of a balance pad and/or similar equipment using an external focus was more effective on producing postural control compared to training with an internal focus using one's ankles.

Clinically, single-task treadmill gait training (TGT) with use of repetition and various gait speeds are used for goals to improve gait speeds and cadence, and changes in balance abilities, confidence, functional gait, and overall physical ability has not been able to be fully evaluated [6,20,21]. Upon returning back to the community, conditions that require one to perform a complex task effectively may be difficult to cope $[6,9]$, and cause the attention span to be dispersed, and therefore there is a need to investigate whether dual-task gait training with the use of an external target for the purpose of improving postural control and gait abilities will improve not only balance, but also gait in persons with chronic stroke.

Therefore, this study investigated the effect of dual-task training with use of a ball with an external target on gait and balance abilities in persons affected with chronic stroke by comparing the dual-task training group with a single-task training group.

\section{Methods}

\section{Subjects}

This study included fourteen patients who had been admitted to the A rehabilitation Convalescent Hospital in Seoul, Republic of Korea. Subjects actively agreed to participate in the study after being informed experimental procedures in detail, and were randomly assigned to either the dual-task training group or the single-task training group. Although there were initially 20 subjects, 6 subjects had been excluded due to discharge or refusal to participate, leading to a total of 14 subjects with 7 subjects in each group. Patient allocation was performed by having the subject select a piece of paper from a box that included 7 pieces of paper for each type of group.

Persons who had been diagnosed with stroke at least 6 months ago, thus indicating a chronic stroke, persons who were able to follow instructions and with an Mini-Mental State Examination score of greater than 24 [7], and those who were able to ambulate at least $10 \mathrm{~m}$ independently with or without an assistive device were selected to participate in the study [15]. Persons with a heart or orthopedic disorder and those with visual or auditory problems were excluded from this study [15]. The general characteristics of subjects are listed in Table 1. This study was conducted under the ap- 
Table 1. General characteristics of participants $(\mathrm{N}=14)$

\begin{tabular}{lcccc}
\hline \multicolumn{1}{c}{ Characteristic } & DTT group $(\mathrm{n}=7)$ & TGT group $(\mathrm{n}=7)$ & $\mathrm{t} / \chi^{2}$ & $p$ \\
\hline Gender (male/female) & $6 / 1$ & $5 / 2$ & 0.003 & 0.552 \\
Age (y) & $61.4(8.0)$ & $58.0(5.6)$ & 0.994 & 0.375 \\
Post-stroke duration (mo) & $38.1(23.4)$ & $36.5(20.2)$ & 0.702 & 0.895 \\
Etiology (infarction/hemorrhage) & $4 / 3$ & $5 / 2$ & & \\
Side of hemiparesis (right/left) & $4 / 3$ & $2 / 5$ & & 0.876 \\
MMSE-K & $26.7(1.9)$ & $26(2.0)$ & & 0.897 \\
\hline
\end{tabular}

Values are presented as number only or mean (SD).

DTT: dual task training, TGT: treadmill gait training, MMSE-K: Mini-Mental State Examination-Korean.

proval of the Baekseok University research ethics committee (BUIRB-201608-HR-018).

\section{Intervention}

All subjects in both groups received gait training for a total of 12 times over 4 weeks ( 30 minutes per day, three times a week), and also received general physical therapy for one hour comprised of range of motion, strength, balance training for an equivalent length of time. The patients were divided into either the ball kicking dual task training (DTT) group or the TGT group (Appendix).

\section{Outcome measures}

There were six clinical outcome measures used to assess balance and gait through the ball kicking DTT intervention in persons with chronic stroke. The 10-meter walking test (10MWT), the 6-minute walking test (6MWT), and the functional gait assessment (FGA) were used to evaluate gait while balance was assessed with the Berg balance scale (BBS), timed up and go test (TUG), and the activities-specific balance confidence (ABC) scale. All evaluations were performed prior to the intervention as well as after 4 weeks of gait training, 3 times a week.

\section{MWT}

Being considered as a safe method for evaluating gait, the 10MWT was used in order to assess the gait speed of the persons affected with stroke [8]. This evaluation involved having the subject ambulate $14 \mathrm{~m}$ at a comfortable speed, and in order to eliminate the effects of acceleration and deceleration, data from the first and last $2 \mathrm{~m}$ has been omitted while data from the middle $6 \mathrm{~m}$ has been measured, and the average value was obtained from three trials $[22,23]$. The reliability of the 10MWT has been reported to be $r=0.99$ [24].

\section{MWT}

Gait endurance was assessed using the 6MWT. This is an endurance assessment tool where the subject is instructed to walk across a distance of $20 \mathrm{~m}$ repeatedly for 6 minutes and measures the total distance. Rather than being conducted on a round track or ramps, the 6MWT was performed on a plain. The reliability for the $6 \mathrm{MWT}$ has been reported to be $\mathrm{r}=0.94$ [25].

\section{FGA}

As a modified version of the dynamic gait index, this tool is used to assess postural control a person in response to the danger of falls and evaluates how well a person is able to have postural control [26]. With a total of 10 items, each item can be scored on a four-point scale (0-3 points), and considering 30 points being the maximum, a score of less than 22 points is considered as having a high risk for falls [27]. The reliability of the FGA has been reported to be $\mathrm{r}=0.93$ [28].

\section{BBS}

This assessment tool is comprised of 14 single tasks, each item can be scored on a 5-point scale (0-4 points), and a score of 45 out of 56 points indicate a high risk of falls. It has been reported that the intra-rater reliability and inter-rater reliability for the BBS is $\mathrm{r}=0.99$ and $\mathrm{r}=0.98$ respectively when being used to evaluate persons affected with stroke [3,29].

\section{TUG}

The TUG was used to assess dynamic balance and functional mobility. This test evaluates for dynamic balance by having a person stand up from sitting on a chair with armrests, walk $3 \mathrm{~m}$, turn around, and walk $3 \mathrm{~m}$ back to sit on the chair while being timed. A TUG score of less than 20 seconds indicates independent ability to walk, a score of over 30 
seconds is reported to imply greater dependency, and the reliability of the TUG is reported to be $\mathrm{r}=0.99$ when the assessment is performed on persons with stroke [30].

\section{$A B C$}

This assessment tool consists of 16 items where each item is comprised of either a walking or position-changing activity. The subjects themselves rate their level of confidence while trying to balance for each item. Scores can be graded on increments of $10 \%$ from $0 \%$ (not confident at all) to $100 \%$ (very confident), and the total score is divided by 16 to represent the confidence level. A score of greater than 81.1 points indicates having no fall experience [31]. This assessment tool has a test-retest reliability of $\mathrm{r}=0.87[32,33]$.

\section{Data analysis}

The data collected for this study were statistically processed using the PASW Statistics ver. 18.0 (IBM Co., Armonk, NY, USA) program, and the Kolmogorov-smirnov test was used to confirm a normal distribution. The independent t-test was used to investigate for any differences in general characteristics between groups, the paired t-test was used for pre-post test comparisons within groups, and the independent t-test was used to investigate for pre-post test differences between groups. The significance level was set at $\alpha=0.05$.

\section{Results}

Between the DTT and the TGT groups, the differences and change values for the $0.17 \pm 0.09 \mathrm{~m} / \mathrm{s}$ for the $10 \mathrm{MWT}$, $31.43 \pm 3.44 \mathrm{~m}$ for the $6 \mathrm{MWT}, 1.43 \pm 0.28$ points for the FGA, $2.71 \pm 0.95$ points for the BBS, $2.79 \pm 0.52 \mathrm{sec}$ for the $\mathrm{TUG}$, and $2.73 \pm 1.35$ points for the $\mathrm{ABC}$. There was a greater statistically significant improvement in gait and balance in the DTT group $(p<0.05$; Tables 2, 3).

Within the DTT group, the pre-post intervention change values were $0.28 \pm 0.16 \mathrm{~m} / \mathrm{s}$ for the $10 \mathrm{MWT}, 54.36 \pm 22.45 \mathrm{~m}$ for the $6 \mathrm{MWT}, 4.43 \pm 0.53$ points for the FGA, $6.71 \pm 1.50$ points for the BBS, $4.35 \pm 1.16 \mathrm{sec}$ for the TUG test, and $5.62 \pm 2.04$ points for the $\mathrm{ABC}$, with greater improvement in gait and balance abilities and all change values were statistically significant ( $p<0.05$; Tables 2,3$)$.

Within the TGT group, the pre-post intervention change values were $0.11 \pm 0.07 \mathrm{~m} / \mathrm{s}$ for the 10MWT, $22.93 \pm 19.00 \mathrm{~m}$ for the $6 \mathrm{MWT}, 3.00 \pm 0.82$ points for the FGA, $5.00 \pm 2.45$ points for the BBS, $1.56 \pm 1.68 \mathrm{sec}$ for the TUG test, and $2.89 \pm 0.70$ points for the $\mathrm{ABC}$, with greater improvement in gait and balance abilities and all change values were statistically significant $(p<0.05$; Tables 2,3$)$.

Table 2. Comparison of clinical evaluations for gait performance during dual task gait training and treadmill gait training ( $\mathrm{N}=14)$

\begin{tabular}{|c|c|c|c|c|c|c|c|}
\hline & \multicolumn{3}{|c|}{ DTT group $(n=7)$} & \multicolumn{3}{|c|}{ TGT group $(n=7)$} & \multirow{2}{*}{$p$} \\
\hline & Pre & Post & $p$ & Pre & Post & $p$ & \\
\hline 10MWT (m/s) & $0.66(0.21)$ & $0.94(0.36)$ & 0.003 & $0.63(0.20)$ & $0.74(0.26)$ & 0.006 & 0.016 \\
\hline 6MWT (m) & $203.74(75.71)$ & $258.10(78.64)$ & 0.001 & $206.42(51.72)$ & $229.35(62.04)$ & 0.019 & 0.015 \\
\hline FGA (score) & $16.85(4.14)$ & $21.28(3.68)$ & $<0.001$ & $15.28(5.34)$ & $18.28(5.15)$ & $<0.001$ & 0.002 \\
\hline
\end{tabular}

Values are presented as mean (SD).

DTT: dual task training, TGT: treadmill gait training, 10MWT: 10-meter walking test, 6MWT: 6-minute walking test, FGA: functional gait assessment.

Table 3. Comparison of clinical evaluation for balance ability during dual task gait training and treadmill gait training (N=14)

\begin{tabular}{|c|c|c|c|c|c|c|c|}
\hline & \multicolumn{3}{|c|}{ DTT group $(n=7)$} & \multicolumn{3}{|c|}{ TGT group $(n=7)$} & \multirow{2}{*}{$p$} \\
\hline & Pre & Post & $p$ & Pre & Post & $p$ & \\
\hline BBS (score) & $38.00(3.36)$ & $44.71(3.35)$ & $<0.001$ & $33.42(4.23)$ & $38.42(3.10)$ & 0.005 & 0.028 \\
\hline TUG (sec) & $21.91(6.30)$ & $17.56(5.54)$ & $<0.001$ & $19.96(7.70)$ & $18.40(7.83)$ & 0.049 & 0.004 \\
\hline ABC scale (score) & $63.84(11.91)$ & $69.46(11.84)$ & $<0.001$ & $54.96(18.90)$ & $57.85(18.76)$ & $<0.001$ & 0.006 \\
\hline
\end{tabular}

Values are presented as mean (SD).

DTT: dual task training, TGT: treadmill gait training, BBS: Berg balance scale, TUG: timed up and go test, ABC scale: activities-specific balance confidence scale. 


\section{Discussion}

The purpose of this study was to investigate the effects of performing dual-task training with use of a ball on gait and balance abilities in persons with chronic stroke and to compare the effects with the current gait training method with use of a treadmill. The results have shown greater improvements in gait and balance abilities with dual-task training with use of a ball compared to the current TGT method.

Sim and Oh [34] reported significant differences in gait velocity with cognitive-motor dual-task training compared with single-task training, and that subjects exhibited improved gait velocity, endurance, static and dynamic balance abilities after training. Since gait speed is not the only factor that determines one's ability to walk within the community, other physical, cognitive, and emotional factors should be considered [35]. In this study, improvements in gait speed was due to performing dual-task gait training that combined physical and cognitive challenges, and rather than only improvements in gait speed, gait endurance and balance abilities were also improved as similarly shown from previous studies.

A study by Silsupadol et al. [3] reported improved balance and gait speeds in elderly subjects with impaired balance and reduced gait speeds after performing dual-task training with eyes closed, hand movements while standing, and other various physical activities in addition to performing cognitive tasks, such as trying to recall object names or numbers.

Previous studies show that dual-task training increases task-coordination skills with improvement being due to the ability to incorporate the challenges efficiently. For this particular study, it is considered that subjects who underwent gait training while counting backwards showed improvements in gait and balance abilities due to the coordination and integration of motor and cognitive tasks as shown in previous studies. Therefore, it is believed to be necessary to provide an environment for persons with stroke to exercise while inducing their memory or to perform motor tasks while talking.

Balance ability is considered to be an indicator for fall risk [1,3], and Shumway-Cook et al. [36] stated that the balance can be evaluated and the danger of falls can be predicted through the BBS where a score of less than 36 points implies close to a $100 \%$ risk of falls within the elderly population. In addition, the results of this study where improved balance ability, balance confidence, and gait ability occurred post in- tervention are compatible with previous studies that report reduced risk of falls with balance improvement through postural control [3].

Increased risk of falls due to loss of balance or balance confidence levels can be predicted through self-efficacy, which can be assessed with the ABC scale.

A study by Salbach et al. [32] conducted a study where persons with stroke perform dual-task oriented exercises three times a week for 6 weeks and showed a 13.9\% increase in self-efficacy compared to the control group and reported that higher levels of self-efficacy were correlated with increased gait endurance. In addition, based on the reports of improved balance abilities in the post dual-task training group compared to the single-task training group by Jung and Won [6], it has been observed that balance abilities, balance confidence, and gait endurance have an effect on each other. This study can support the positive effects of dual-task training since results have shown improved gait endurance and self-efficacy in the DTT group compared to the TGT group.

For persons with stroke who have movement and cognitive impairments, it is necessary for them to walk and exercise or perform a cognitive task simultaneously for the prevention of falls during the performance of daily life activities [7]. Choi et al. [16] reported improved dynamic balance abilities in dual-task training treadmill training group that followed audible instructions to transfer rings compared to the TGT group. Although increased double-limb support time and decreased gait speeds had been observed in those who walked and followed audible instructions to memorize numbers and count backwards simultaneously for dual-task training [2], since motor-cognitive gait training brings about improvements in gait speeds as an executive function [37], the study results have shown the need for repetitive dual-task training for gait and balance improvements.

The results of this study showed improved gait speeds and dynamic balance in the DTT with use of a ball compared to the single-task TGT group, which are compatible with the results from previous studies.

The cognitive area includes attention, planning, remembering, problem solving, use of speech, etc. and because it is difficult to produce movement without these elements, the cognitive process plays an important role in movement control. Studies show that dual-task performance that includes cognitive and gait components improve attention capacity and functional movements in those with neurological impairments [4,38]. However, depending on the environ- 
ment, if the cognitive process of attention and concentrations are not properly induced, this can lead to reduced gait speeds, indicating an interdependent relationship between cognitive function and gait [34].

For this study, the advantages of using a ball were not only improvement of general physical ability of the subjects, assisting to integrate motor tasks in a complex environment, and providing feedback, but it also promoted the subject's interest and active participation, which has contributed to improvements in gait performance [12].

The use of a ball for dual task gait training is considered to have a positive effect on improving gait and balance abilities due to the promotion of patient interest in participating and improvements in the degree of concentration.

This study was aimed to improve the gait and balance abilities of the subjects through the use of a ball with exercise combined with the addition of a cognitive task, which has led to improved concentration and attention, and was conducted based on findings from previous studies that have shown an effect on task performance accuracy [34]. Previous studies have shown that walking with concentration placed externally, such as the relocation of eggs without dropping them, or movement of cups filled with water without spilling, has shown improvements in gait and balance abilities in the experimental group compared to the control group, and is reported to provide a positive effect on the patient's walking performance due to the promotion of changes in concentration and attention levels, assist to improve the accuracy of learning various tasks with dual-task training [34]. In addition, in regards to subjects with balance impairments due to neurological diseases, results show that posture control was more efficient with use of an external focus compared to an internal focus for concentration [19]. Therefore, it is considered that through the combination of an external focus on a target and cognitive tasks, the gait and balance abilities of subjects had improved more compared to the subjects who had undergone the single-task TGT. The limitations of this study were a small number of subjects, making it difficult to generalize the results to all persons with stroke, and since there was no follow-up process, the extent of the training effect is unknown. Also, although cognitive tasks were added to the motor tasks performed, differences in cognitive abilities, concentration, and coordination abilities before and after intervention had not been assessed. Therefore, further studies will need to include a larger number of subjects, evaluate the cognitive function ability, concentration, and coordination prior to and after intervention, and include a follow-up process.

The purpose of this study was to investigate the effects of ball-kicking DTT, three times a week for four weeks, on gait and balance ability in persons affected by chronic stroke. The training methods have been divided into three steps, and cognitive tasks were included in step two to adjust the difficult level. Results showed that gait speed, endurance, static and dynamic balance, and balance confidence values were more improved after dual-task training compared to single-task training. Since exercise and cognitive function are both reduced in persons with stroke, dual-task training that combines the two elements is necessary, and physical function will be improved through the distribution of their attention while walking and performing a dual-task.

\section{Conflict of Interest}

The authors declared no potential conflicts of interest with respect to the authorship and/or publication of this article.

\section{References}

1. Bayouk JF, Boucher JP, Leroux A. Balance training following stroke: effects of task-oriented exercises with and without altered sensory input. Int J Rehabil Res 2006;29:51-9.

2. Bowen A, Wenman R, Mickelborough J, Foster J, Hill E, Tallis R. Dual-task effects of talking while walking on velocity and balance following a stroke. Age Ageing 2001;30:319-23.

3. Silsupadol P, Shumway-Cook A, Lugade V, van Donkelaar P, Chou LS, Mayr U, et al. Effects of single-task versus dual-task training on balance performance in older adults: a double-blind, randomized controlled trial. Arch Phys Med Rehabil 2009;90: 381-7.

4. Kim GY, Han MR, Lee HG. Effect of dual-task rehabilitative training on cognitive and motor function of stroke patients. J Phys Ther Sci 2014;26:1-6.

5. Yang YR, Yen JG, Wang RY, Yen LL, Lieu FK. Gait outcomes after additional backward walking training in patients with stroke: a randomized controlled trial. Clin Rehabil 2005;19:264-73.

6. Jung SR, Won JI. Effects of dual-task training on balance and gait performance in patients with stroke. Phys Ther Korea 2014;21: 18-27.

7. Cho JC, Lee ES, Lee SW. Effects of body weight-supported treadmill training combined with ball kicking on balance and gait of subacute stroke patients. Phys Ther Rehabil Sci 2015;4:73-8.

8. Bohannon RW. Comfortable and maximum walking speed of adults aged 20-79 years: reference values and determinants. Age Ageing 1997;26:15-9.

9. Kim H, Choi W, Lee K, Song C. Virtual dual-task treadmill training using video recording for gait of chronic stroke survivors: a randomized controlled trial. J Phys Ther Sci 2015;27:3693-7.

10. Olney SJ, Richards C. Hemiparetic gait following stroke. Part I: 
characteristics. Gait Posture 1996;4:136-48.

11. Kim HA, Lee HM, Seo KC. The effects of dual-motor task training on the gait ability of chronic stroke patients. J Phys Ther Sci 2013;25:317-20.

12. Yang YR, Wang RY, Chen YC, Kao MJ. Dual-task exercise improves walking ability in chronic stroke: a randomized controlled trial. Arch Phys Med Rehabil 2007;88:1236-40.

13. Plummer-D'Amato P, Altmann LJ, Saracino D, Fox E, Behrman $\mathrm{AL}$, Marsiske M. Interactions between cognitive tasks and gait after stroke: a dual task study. Gait Posture 2008;27:683-8.

14. Baetens T, De Kegel A, Palmans T, Oostra K, Vanderstraeten G, Cambier D. Gait analysis with cognitive-motor dual tasks to distinguish fallers from nonfallers among rehabilitating stroke patients. Arch Phys Med Rehabil 2013;94:680-6.

15. Yu KH, Jeon HS. The effects of dual-task gait training on gait performance under cognitive tasks in chronic stroke. J Korean Phys Ther 2015;27:364-8.

16. Choi W, Lee G, Lee S. Effect of the cognitive-motor dual-task using auditory cue on balance of surviviors with chronic stroke: a pilot study. Clin Rehabil 2015;29:763-70.

17. Lee GC, Choi WJ. The effects of dual-task training on ambulatory abilities of stroke patients: review of the latest trend. Phys Ther Rehabil Sci 2012;1:1-5.

18. Plummer-D'Amato P, Kyvelidou A, Sternad D, Najafi B, Villalobos RM, Zurakowski D. Training dual-task walking in community-dwelling adults within 1 year of stroke: a protocol for a single-blind randomized controlled trial. BMC Neurol 2012;12:129.

19. Wulf G, Landers M, Lewthwaite R, Töllner T. External focus instructions reduce postural instability in individuals with Parkinson disease. Phys Ther 2009;89:162-8.

20. Patterson SL, Rodgers MM, Macko RF, Forrester LW. Effect of treadmill exercise training on spatial and temporal gait parameters in subjects with chronic stroke: a preliminary report. J Rehabil Res Dev 2008;45:221-8.

21. Pohl M, Mehrholz J, Ritschel C, Rückriem S. Speed-dependent treadmill training in ambulatory hemiparetic stroke patients: a randomized controlled trial. Stroke 2002;33:553-8.

22. Collen FM, Wade DT, Bradshaw CM. Mobility after stroke: reliability of measures of impairment and disability. Int Disabil Stud 1990;12:6-9.

23. Dean CM, Richards CL, Malouin F. Walking speed over 10 metres overestimates locomotor capacity after stroke. Clin Rehabil 2001; 15:415-21.

24. Wolf SL, Catlin PA, Gage K, Gurucharri K, Robertson R, Stephen K. Establishing the reliability and validity of measurements of walking time using the Emory Functional Ambulation Profile. Phys Ther 1999;79:1122-33.
25. Mossberg KA. Reliability of a timed walk test in persons with acquired brain injury. Am J Phys Med Rehabil 2003;82:385-90.

26. Wrisley DM, Marchetti GF, Kuharsky DK, Whitney SL. Reliability, internal consistency, and validity of data obtained with the functional gait assessment. Phys Ther 2004;84:906-18.

27. Wrisley DM, Kumar NA. Functional gait assessment: concurrent, discriminative, and predictive validity in communitydwelling older adults. Phys Ther 2010;90:761-73.

28. Walker ML, Austin AG, Banke GM, Foxx SR, Gaetano L, Gardner LA, et al. Reference group data for the functional gait assessment. Phys Ther 2007;87:1468-77.

29. Berg K, Wood-Dauphine S, Williams JI, Gayton D. Measuring balance in the elderly: preliminary development of an instrument. Physiother Can 1989;41:304-11.

30. Podsiadlo D, Richardson S. The timed "Up \& Go": a test of basic functional mobility for frail elderly persons. J Am Geriatr Soc 1991;39:142-8

31. Beninato M, Portney LG, Sullivan PE. Using the International Classification of Functioning, Disability and Health as a framework to examine the association between falls and clinical assessment tools in people with stroke. Phys Ther 2009;89:816-25.

32. Salbach NM, Mayo NE, Robichaud-Ekstrand S, Hanley JA, Richards CL, Wood-Dauphinee S. The effect of a task-oriented walking intervention on improving balance self-efficacy poststroke: a randomized, controlled trial. J Am Geriatr Soc 2005;53: 576-82.

33. Cleary KK, Skornyakov E. Reliability and internal consistency of the activities-specific balance confidence scale. Phys Occup Ther Geriatr 2014;32:58-67.

34. Sim SM, Oh DW. Effect of dual-task training with cognitive motor task on walking and balance functions in patients with chronic stroke: randomized controlled pilot study. Phys Ther Korea 2015;22:11-20

35. van de Port IG, Kwakkel G, Lindeman E. Community ambulation in patients with chronic stroke: how is it related to gait speed? J Rehabil Med 2008;40:23-7.

36. Shumway-Cook A, Baldwin M, Polissar NL, Gruber W. Predicting the probability for falls in community-dwelling older adults. Phys Ther 1997;77:812-9.

37. Plummer P, Villalobos RM, Vayda MS, Moser M, Johnson E. Feasibility of dual-task gait training for community-dwelling adults after stroke: a case series. Stroke Res Treat 2014. doi: $10.1155 / 2014 / 538602$.

38. Hwang WJ, Cho MK, Chung Y. Relationship between anticipatory postural adjustment of the trunk, dual tasks and physical performance with chronic stroke survivors: a pilot test. Phys Ther Rehabil Sci 2015;4:44-8. 